SATHER CLASSICAL LECTURES

Volume Twenty-seven

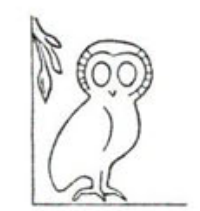

The GREEK ATTITUDE to Poetry and History 


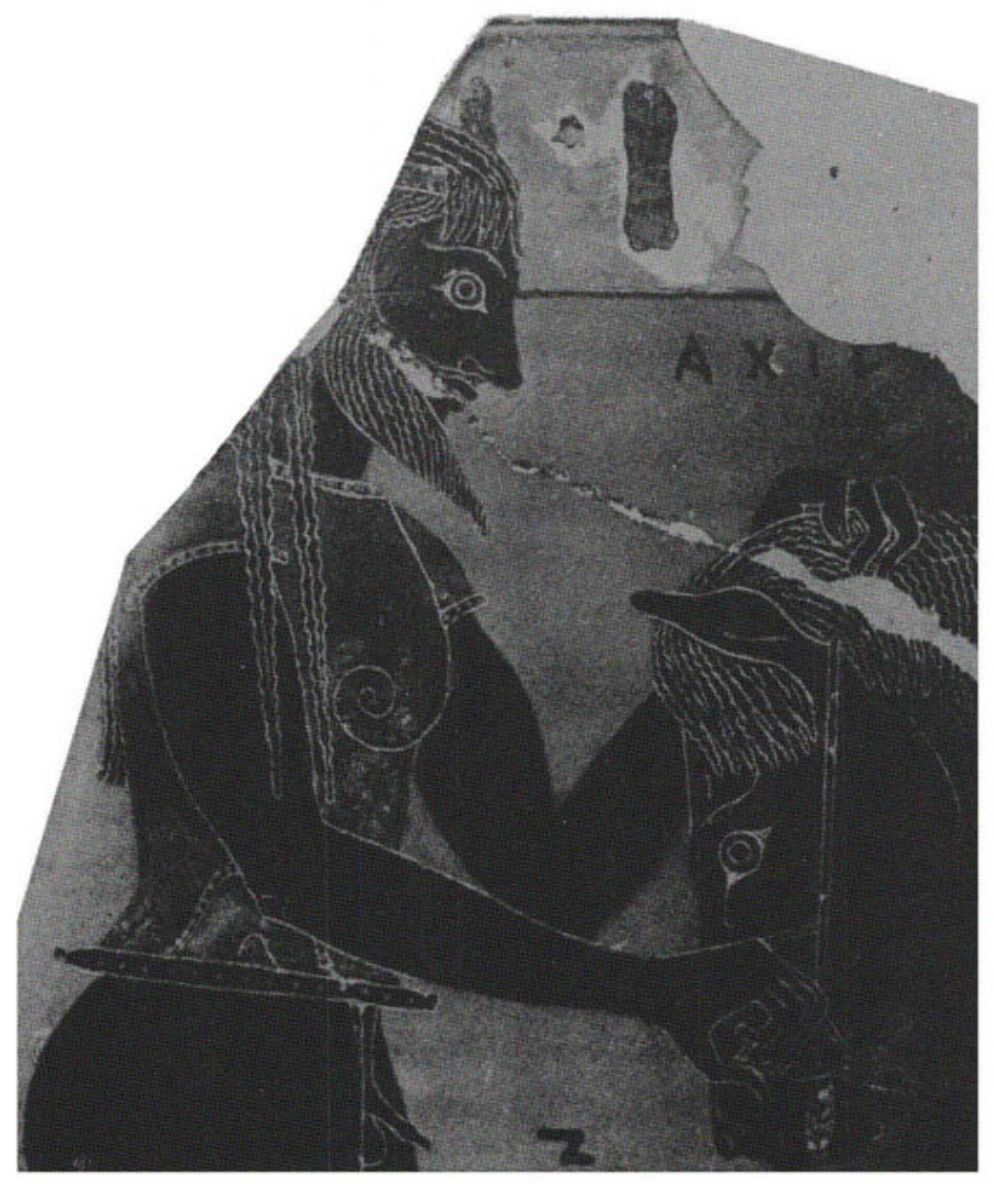

Achilles with his horse Xanthos Fragment of a kantharos by Nearchos Athens Acr. 6II 


\title{
The \\ GREEK ATTITUDE to Poetry and History
}

\author{
By
}

A. W. GOMME

UNIVERSITY OF CALIFORNIA PRESS

Berkeley and Los Angeles: 1954 
University of California Press

Berkeley and Los Angeles

California

Cambridge University Press

London, England

Copyright, r954, by

The Regents of the University of California

Printed in the United States of America By the University of California Printing Department L. C. Catalog Card No. 54-647I 